\title{
Dopamine Release in Dissociable Striatal Subregions Predicts the Different Effects of Oral Methylphenidate on Reversal Learning and Spatial Working Memory
}

\author{
Philip L. Clatworthy, ${ }^{1,2}$ Simon J. G. Lewis, ${ }^{1}$ Laurent Brichard, ${ }^{2 *}$ Young T. Hong, ${ }^{2 \star}$ David Izquierdo, ${ }^{2 *}$ Luke Clark, ${ }^{1}$ \\ Roshan Cools, ${ }^{1,4}$ Franklin I. Aigbirhio, ${ }^{1,2}$ Jean-Claude Baron, ${ }^{1,2,5}$ Timothy D. Fryer, ${ }^{1,2}$ and Trevor W. Robbins ${ }^{1,3}$ \\ ${ }^{1}$ Behavioural and Clinical Neuroscience Institute, ${ }^{2}$ Wolfson Brain Imaging Centre, and ${ }^{3}$ Department of Experimental Psychology, University of Cambridge, \\ Cambridge CB2 3EB, United Kingdom, ${ }^{4}$ Donders Institute for Brain, Cognition, and Behaviour, Radboud University Nijmegen Medical Centre, Nijmegen \\ $6500 \mathrm{HB}$, The Netherlands, and ${ }^{5}$ Department of Clinical Neurosciences, University of Cambridge School of Clinical Medicine, Cambridge CB2 2QQ, United \\ Kingdom
}

Previous data suggest that methylphenidate can have variable effects on different cognitive tasks both within and between individuals. This is thought to be underpinned by inverted U-shaped relationships between cognitive performance and dopaminergic activity in relatively separate fronto-striatal circuits and reflected by individual differences in trait impulsivity. Direct evidence for this is currently lacking. In this study, we demonstrate for the first time that therapeutic doses of oral methylphenidate administered to young healthy subjects result in different sized changes in $\mathrm{D}_{2} / \mathrm{D}_{3}$ receptor availability in different regions of the human striatum and that the change in receptor availability within an individual subregion predicts cognitive performance on a particular task. Methylphenidate produced significantly different effects on reversal learning and spatial working memory tasks within individuals. Performance on the reversal learning task was predicted by the drug-induced change in $\mathrm{D}_{2} / \mathrm{D}_{3}$ receptor availability in postcommissural caudate, measured using $\left[{ }^{11} \mathrm{C}\right]$-raclopride radioligand PET imaging, whereas performance on the spatial working memory task was predicted by changes in receptor availability in the ventral striatum. Reversal learning performance was also predicted by subjects' trait impulsivity, such that the most impulsive individuals benefited more from methylphenidate, consistent with this drug's beneficial effects on cognition in attention deficit hyperactivity disorder.

\section{Introduction}

Psychostimulants such as the indirect catecholamine agonists amphetamine and methylphenidate are major treatments ameliorating cognitive dysfunction in attention deficit hyperactivity disorder (ADHD) (Kempton et al., 1999; Mehta et al., 2000; Aron et al., 2003; Bedard et al., 2003). Ascending mesencephalic dopa-

Received July 12, 2008; revised Jan. 4, 2009; accepted Feb. 4, 2009.

This work was completed within the Behavioral and Clinical Neurosciences Institute at the University of Cambridge, UK, supported by a joint award from the Medical Research Council (UK) and the Wellcome Trust. We thank the radiographers and cyclotron staff at the Wolfson Brain Imaging Centre for assistance with data acquisition, Dr. Mike Aitken for statistical advice, Dr. Andrew Blackwell for neuropsychological testing advice, Simon Jones for practical assistance with image analysis, and Dr. Ulrich Muller for comments on this manuscript. Author contributions are as follows: P.L.C., performance of most experiments, data analysis, and manuscript preparation; S.J.G.L., assistance with study design and carrying out the initial phase of the study; L.B., $\left[{ }^{11} \mathrm{C}\right]$-raclopride production, including assistance with development of production; Y.T.H., PET data modeling; D.I., implementation of partial volume correction; L.C., assistance with study design, data analysis, and manuscript preparation; R.C., assistance with study design and manuscript preparation; F.I.A., production and direction of production of [ $\left.{ }^{11} \mathrm{C}\right]$-raclopride; J.-C.B., assistance with study design, overall supervision of PET program, and manuscript preparation; T.D.F., assistance with study design, direction of PET imaging and analysis; T.W.R., overall direction of the project.

T.W.R. and L.C. receive fees for consultation work with Cambridge Cognition Limited.

*L.B., Y.T.H., and D.I. contributed equally to this work.

This article is freely available online through the J Neurosci Open Choice option.

Correspondence should be addressed to Prof. Trevor W. Robbins, Behavioural and Clinical Neuroscience Institute, Department of Experimental Psychology, University of Cambridge, Downing Site, Cambridge CB2 3EB, UK. E-mail: twr2@cam.ac.uk.

DOI:10.1523/JNEUROSCI.3266-08.2009

Copyright $\odot 2009$ Society for Neuroscience $\quad$ 0270-6474/09/294690-07\$15.00/0 mine projections to striatum and prefrontal cortex (PFC) are implicated in working memory, cognitive flexibility, and reinforcement learning. The striatum's importance in human cognition has been shown by neuropsychological (Robbins et al., 1998) and functional neuroimaging (Vaidya et al., 1998; Cools et al., 2004; Lewis et al., 2004; Dodds et al., 2008) studies. Methylphenidate's effects on striatal dopamine are quantifiable using positron emission tomography (PET), notably using the $\mathrm{D}_{2} / \mathrm{D}_{3}$ receptor antagonist radioligand $\left[{ }^{11} \mathrm{C}\right]$-raclopride (Volkow et al., 2001). Drug-induced increases in extracellular dopamine reduce dopamine receptor availability, resulting in a measurable reduction in radioligand binding. Here, we used $\left[{ }^{11} \mathrm{C}\right]$-raclopride PET to explore the relationship between different cognitive effects of methylphenidate and dopamine $\mathrm{D}_{2} / \mathrm{D}_{3}$ receptor binding within dissociable striatal subregions in healthy humans.

Evidence suggests that relatively separate neocortical regions subserve cognitive tasks such as reversal learning (Dias et al., 1996) and spatial working memory (SWM) (Williams and Goldman-Rakic, 1995). The distribution of these regions' striatal projections (Divac et al., 1967; Haber et al., 2006) makes it likely that these tasks' striatal substrates are also relatively distinct, although diffuse connections between PFC and striatum also exist (Haber et al., 2006). Striatal $\mathrm{D}_{2} / \mathrm{D}_{3}$ receptors are specifically implicated in SWM and reversal learning in monkeys (von Huben et al., 2006; Lee et al., 2007). In healthy humans, the $\mathrm{D}_{2}$ receptor 
agonist bromocriptine has different effects on spatial memory and reversal learning (Mehta et al., 2001), which can be both detrimental and beneficial in different individuals (Kimberg et al., 1997). Such effects can be explained by different hypothesized "inverted U"-shaped relationships between performance on different tasks and PFC dopamine, at the systems (Williams and Goldman-Rakic, 1995; Mattay et al., 2003; Roberts et al., 1994) or cellular (Vijayraghavan et al., 2007) levels. Such relationships have been postulated in humans (Cools et al., 2001, 2007a) but not demonstrated for the striatum.

The present study used neurocognitive measures of reversal learning (Swainson et al., 2000) and SWM (Owen et al., 1990), sensitive to methylphenidate challenge in healthy adults (Mehta et al., 2000, 2001; Dodds et al., 2008), alongside PET measurement of striatal dopamine receptor availability, assayed using $\left[{ }^{11} \mathrm{C}\right]$-raclopride displacement, reflecting drug-induced dopamine release. We hypothesized that methylphenidate would evoke $\left[{ }^{11} \mathrm{C}\right]$-raclopride displacement in caudate, putamen, and ventral striatum, consistent with studies using intravenous amphetamine (Drevets et al., 2001; Martinez et al., 2003). We predicted that changes in $\left[{ }^{11} \mathrm{C}\right]$-raclopride binding potential (BP), a measure of receptor availability, in distinct striatal subregions would correlate with different cognitive effects of methylphenidate, consistent with the hypothesis of relatively distinct frontostriatal substrates for different cognitive processes. As trait impulsivity moderated bromocriptine's effect on cognition (task switching) and striatal neural activity [measured with functional MRI (fMRI)] (Cools et al., 2007b), we further hypothesized that these drug effects would vary with trait impulsivity.

\section{Materials and Methods}

Subject recruitment and summary of study procedure. Ten healthy male subjects (age 22-32 years) were recruited via public poster advertisements. Exclusion criteria were previous drug use or any history of psychiatric or neurological illness. Subjects underwent an initial training session at which both of the neuropsychological tests described below were administered. They then visited on two subsequent occasions, at least $72 \mathrm{~h}$ apart, on each of which they received methylphenidate $(60 \mathrm{mg}$, oral; DHP Pharma) or placebo according to a double-blind, crossover design. On each session, they also underwent $\left[{ }^{11} \mathrm{C}\right]$-raclopride PET scanning that commenced 60 min after capsule ingestion; immediately after scanning, they performed the neuropsychological tests described. Blood pressure and heart rate, and subjective affect [Positive and Negative Affect Scale (PANAS)], were measured at $30 \mathrm{~min}$ intervals from $30 \mathrm{~min}$ before drug administration, including during PET scanning. Visual analog scales were used to measure euphoric and drug-seeking responses to methylphenidate. Drug effects on blood pressure and visual analog scale scores were measured as mean change from session baseline across the period of drug effect. Trait impulsivity was measured using the selfreport Barratt Impulsiveness Scale (BIS-11) (Patton et al., 1995), which was administered before scanning. The study was approved by the Cambridge Local Research Ethics Committee and was conducted in accordance with the Declaration of Helsinki.

Cognitive assessment. Cognitive effects of methylphenidate were assessed with two tasks, reversal learning and spatial working memory. Tasks were administered on a personal computer with a 10.5 inch touch sensitive monitor, and responses on both tasks were recorded using touch-screen control.

Reversal learning (Swainson et al., 2000). The reversal learning task was used to assess the acquisition and flexible adaptation of a stimulusreinforcement association. On each trial, the subject was presented with two stimuli, one red and one green, which appeared randomly in two of four spatial locations on the monitor. The subject was required to select one of the two stimuli on each trial, after which feedback was provided in the form of the word "correct" or "incorrect" on the screen and a high or low tone, respectively. The subject was unaware of which colored box was designated correct and was required to learn the stimulus-reward association by trial and error. The correct stimulus was arbitrarily designated as the subject's first response. In the initial 40 trials (stage 1, acquisition), the designation of the correct stimulus did not change, but on a proportion of trials (25\%), the subject received misleading probabilistic feedback such that the correct response resulted in incorrect feedback and vice versa. After 40 acquisition trials, the stimulus-outcome contingencies reversed for a further 40 trials (stage 2, reversal), such that the initially reinforced stimulus now yielded negative feedback, and the initially incorrect stimulus now yielded positive feedback. The proportion of trials with probabilistic feedback remained the same. The subject was required to identify when the rule reversal had occurred and change his response pattern accordingly. The performance measure used was the difference between the number of errors during stage 1 (acquisition) and stage 2 (reversal), i.e., reversal errors controlling for acquisition errors.

SWM (Owen et al., 1990). The SWM task is a self-ordered search task, taken from the Cambridge Neuropsychological Test Automated Battery. The subject was presented with a number of boxes on the computer screen; behind one of the boxes was hidden a token. The subject was required to find the token by selecting boxes on the touch-sensitive screen. Once the token had been found, it was then hidden behind a different box. The subject was instructed that within a trial, the token would not be hidden behind the same box twice. To carry out the task successfully it was, therefore, necessary to remember which of the boxes had previously been used to hide the token. This process was repeated until the token had been hidden behind every box. The test started with three boxes being displayed, this number increasing by one on alternate runs until a maximum of 12 boxes were simultaneously present. The measure of performance used was the total number of between-search errors (i.e., errors where the subject returned to a box that had previously yielded a token).

Image acquisition and processing. PET data were acquired in threedimensional (3D) mode on a GE Advance scanner (GE Medical Systems) for $60 \mathrm{~min}$ (53 time frames) after injection of $\left[{ }^{11} \mathrm{C}\right]$-raclopride. In all cases, the injected activity was such that the injected mass of $\left[{ }^{11} \mathrm{C}\right]$ raclopride represented $<1 \mathrm{nmol} / \mathrm{kg}$ to keep receptor occupancy $<1 \%$ (Hume et al., 1998). A 15 min transmission scan using rotating ${ }^{68} \mathrm{Ge} \mathrm{rod}$ sources was performed before injection to correct for photon attenuation. Corrections for randoms, dead time, sensitivity, and scatter were also applied to the data. Images were reconstructed using 3D-filtered back-projection (Kinahan and Rogers, 1989) into $2.34 \times 2.34 \times 4.25 \mathrm{~mm}$ voxels with a Hanning filter applied transaxially to result in an isotropic resolution at the center of the field of view of $6.8 \mathrm{~mm}$ full-width at half-maximum.

A T1-weighted spoiled gradient recalled echo scan (1 mm cubic voxels) was acquired for each subject on a Bruker 3T MR system to facilitate region of interest (ROI) delineation and partial volume correction. PET images were first realigned using the Statistical Parametric Mapping software package (SPM2; Institute of Neurology, London, UK) to reduce any error resulting from head motion during the PET scan. The mean realigned image was then coregistered to the MR using the normalized mutual information algorithm of SPM2. All the realigned PET images were subsequently resliced to be coregistered with the MR.

Bilateral ROIs were drawn manually on individual subjects' MR images using the Analyze software package (Mayo Clinic). On each side, five striatal ROIs were drawn using the method described by Mawlawi et al. (2001) and Martinez et al. (2003) (Fig. 1). To facilitate partial volume correction, the striatal ROIs were encompassed by an ellipsoidal background region of $\sim 1.5 \mathrm{~cm}$ thickness. Partial volume correction was performed for each resliced PET image using an implementation of the Rousset algorithm (Rousset et al., 1998). The partial volume corrected striatal ROI time-activity curves were used as input into an implementation of the basis function simplified reference tissue model (Gunn et al., 1997) to determine ROI binding potential, with the cerebellum being used as the reference tissue.

The PET metric used in the analysis was percentage BP change from baseline (see Eq. 1). ((Placebo BP - Drug BP)/Placebo BP) $\times 100 \%$ (Eq. 1). Providing there is no change in $\mathrm{D}_{2} / \mathrm{D}_{3}$ receptor density or raclopride affinity between the two PET scans, Equation 1 gives the percentage 
reduction in $\mathrm{D}_{2} / \mathrm{D}_{3}$ receptor availability attributable to the drug-induced increase in synaptic dopamine level.

Data analysis. Cardiovascular and subjective effects of methylphenidate were assessed using paired sample $t$ tests in Statistical Package for the Social Sciences (version 14). Effects of methylphenidate on raclopride binding potential were assessed using a repeated-measures ANOVA with drug (drug vs placebo), hemisphere (left vs right), and region of interest (five levels) as within-subject factors of interest and session order (drug first or placebo first) as a between-subjects factor. Differences in binding potential change (Eq. 1, averaged across hemispheres) between striatal subregions were assessed using post hoc tests on a further repeatedmeasures ANOVA with region of interest as a within-subjects factor and session order as a between-subjects factor, with Bonferroni correction for multiple comparisons. Cognitive effects of methylphenidate were initially assessed using paired sample $t$ tests. The difference in effect of methylphenidate between the two tasks within individuals was assessed using a onesample $t$ test on the size of the difference in the $Z$-score of the drug effect between the tasks. Associations between drug-induced changes in cognitive performance measures, BP change values from each of the five ROIs, and trait impulsivity (BIS-11) were calculated using Kendall's tau-b coefficients, to minimize the influence of outliers on the small sample sizes (Kruskal, 1958).

\section{Results \\ Cardiovascular effects \\ of methylphenidate}

Methylphenidate administration produced significant increases in systolic blood pressure (mean paired difference, $\left.22 \mathrm{mmHg} ; t_{(9)}=4.1 ; p=0.003\right)$ and heart rate (mean paired difference, 9.5 beats per minute; $t_{(9)}=2.4 ; p=0.042$ ) relative to placebo.

\section{Subjective effects of methylphenidate}

Compared with placebo, methylphenidate significantly increased positive affect on the PANAS (mean paired difference, $6.4 ; t_{(9)}=$ $2.9 ; p=0.016$ ), with the drug minus placebo change score varying from -2 to +19 across subjects. Methylphenidate had positive effects on visual analog scales assessing drug liking ("like drug" mean paired difference, $15.9 ; t_{(9)}=4.3 ; p=0.002$ ) and drug wanting ("want drug now" mean paired difference, $25.6 ; t_{(9)}$ $=2.6 ; p=0.029)$. No subject had an aversive response to the drug (range of drug minus placebo like drug, 0-26.5; want drug now, $0-78)$. There was no significant effect on the negative affect subscale of the PANAS $\left(t_{(9)}=0.76 ; p=0.47\right)$ or on a visual analog rating of anxiety $\left(t_{(9)}=1.5 ; p=0.17\right)$. One individual who gave high ratings of anxiety after drug (94.5 of 100) also displayed a strong positive affective response to the drug (drug minus placebo PANAS positive score $=+16$ ).

\section{Regional displacement of $\left[{ }^{11} \mathrm{C}\right]$-raclopride}

Analysis of one individual's PET data from his drug session produced markedly outlying results, particularly in the ventral stria- tum. This individual was the only one to have a substantial anxious response to methylphenidate (see above), and he was seen to move excessively during scanning, resulting in an abnormally shaped PET time activity curve. His PET data were excluded from all analysis.

The magnitude of $\left[{ }^{11} \mathrm{C}\right]$-raclopride displacement (placebo minus drug binding potential relative to placebo) for individual regions of interest in the remaining nine subjects is summarized in Figure 2. A repeated-measures ANOVA revealed no main effect of, or interactions with, hemisphere $(p>0.2)$ or session order (all $p>0.1$ ). Significant main effects were found for the factors $\operatorname{drug}\left(F_{(1,8)}=36.4 ; p=0.001\right)$ and region of interest $\left(F_{(4,5)}=16.3 ; p<0.001\right)$, and importantly there was a significant drug by region interaction $\left(F_{(4,5)}=10.6 ; p<\right.$ 0.001). Post hoc comparisons on the drug-induced BP change scores, collapsed across hemisphere and corrected for multiple comparisons, revealed greater displacement in the postcommissural putamen compared with precommissural putamen [mean difference, $12.0 \%$ (95\% confidence interval, 3.7-20.4); $p=0.007$ ] and precommissural caudate [mean difference, $18.9 \%(0.56-37.2) ; p=0.043]$, and a trend toward greater 


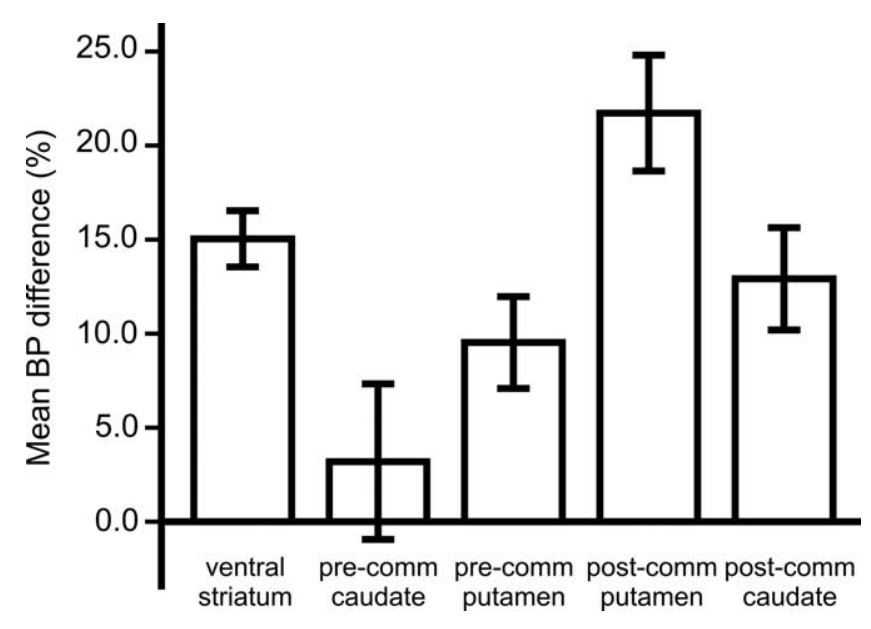

Figure 2. Effect of methylphenidate administration on $\left[{ }^{11} \mathrm{C}\right]$-raclopride binding potential for all striatal regions of interest (see Materials and Methods). Ordinate shows the mean percentage difference in BP (Eq. 1) (Materials and Methods) between drug and placebo sessions. Error bars represent $1 \mathrm{SE}$. pre-comm, Precommissural; post-comm, postcommissural.

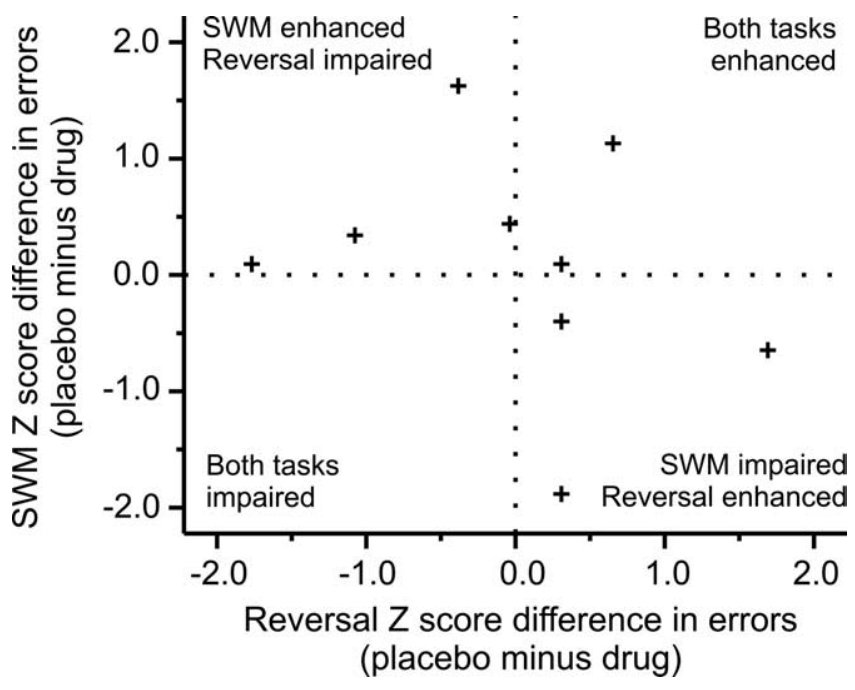

Figure 3. Effects of methylphenidate on reversal learning and SWM. Ordinate shows the $Z$-score for difference in reversal errors, placebo minus methylphenidate. Abscissa shows the equivalent score for between-search errors in the SWM task. Note the difference in drug effects between tasks in most subjects (top left and bottom right quadrants).

displacement in ventral striatum than in precommissural caudate [mean difference, $14.3 \%(-1.5-30.0) ; p=0.081]$.

Effects of methylphenidate on cognitive performance

Methylphenidate did not exert a significant effect on either task across the whole group of subjects; there was no drug effect on reversal learning errors (mean paired difference, drug minus placebo errors $=0.1 ; t_{(8)}=0.12 ; p=0.91$ ) or SWM errors (mean paired difference, drug minus placebo errors $=-1.9 ; t_{(9)}=$ $-0.30 ; p=0.77)$. However, there was a high degree of variability in the drug effects between different individuals as well as between different tasks (Fig. 3). Taking account of this variability, a one-sample $t$ test on the magnitude of the difference in $Z$-scores between the drug effects on the two tasks revealed that methylphenidate had significantly different effects on performance of the two tasks (mean difference, $Z$-score $=1.30 ; t_{(8)}=4.7 ; p=$ $0.002)$. $Z$-scores for the two tasks were not significantly correlated $\left(r^{2}=0.07, p=0.48\right.$; tau $\left.=-0.24, p=0.39\right)$.
Binding potential associations with reversal learning

A significant and strong negative correlation was found between the magnitude of the effects of methylphenidate on $\mathrm{D}_{2} / \mathrm{D}_{3}$ receptor availability in the postcommissural caudate nucleus (relative difference in $\left[{ }^{11} \mathrm{C}\right]$-raclopride $\mathrm{BP}$ between drug and placebo scans) and positive drug effects on reversal performance, such that the subjects with smaller $\left[{ }^{11} \mathrm{C}\right]$-raclopride displacements tended to be improved by drug, whereas those with larger displacements tended to be impaired by drug $\left(r^{2}=0.75, p=0.003\right.$; Kendall's tau-b $=-0.67, p=0.014$ ) (Fig. 4, left). Correlations between $\mathrm{D}_{2} / \mathrm{D}_{3}$ receptor availability changes and reversal performance were not significant in any other striatal region (all tau $\leq$ 0.2 ; all $p>0.4$ ), nor across the whole striatum ( tau $=0.38 ; p=$ $0.17)$.

\section{Trait impulsivity association with cognitive performance}

The effect of methylphenidate on reversal learning also varied as a function of trait impulsivity on the BIS. A significant positive correlation was found between BIS score and the ameliorating effect of methylphenidate on reversal learning, such that the most impulsive individuals benefited most from drug administration $\left(r^{2}=0.46\right.$; Kendall's tau-b $=0.64, p=0.03$ ) (Fig. 4, middle). The mean BIS score was 69 (range, 60-79). A Mann-Whitney $U$ test on drug-induced reduction of reversal errors, with subjects split at median on Barratt Impulsivity Score, showed a significant difference between relatively high and low impulsive subjects $(Z=$ $-2.1 ; p=0.038)$.

No correlation was found between BIS score and SWM performance $(\mathrm{tau}=0.21 ; p=0.46)$ or between BIS score and baseline performance on the reversal learning $(\mathrm{tau}=0.29 ; p=0.35)$ or SWM (tau $=-0.04 ; p=0.90)$ tasks.

\section{Binding potential associations with SWM}

In contrast to the association between binding potential and drug effects on reversal learning, for the spatial working memory task, a significant positive correlation was found between the beneficial effect of methylphenidate on SWM performance and the magnitude of $\left[{ }^{11} \mathrm{C}\right]$-raclopride displacement in the ventral stria$\operatorname{tum}\left(r^{2}=0.44 ;\right.$ Kendall's tau-b $\left.=0.65 ; p=0.016\right)$ (Fig. 4, right). Subjects with relatively small BP changes in this region received less benefit from methylphenidate than those with relatively large BP changes. There was a trend toward a similar correlation between SWM performance and raclopride displacement in the precommissural caudate $\left(r^{2}=0.22\right.$; tau $\left.=0.50 ; p=0.06\right)$. Correlations between $D_{2} / D_{3}$ receptor availability changes and SWM performance were not significant in other striatal regions (all tau $<0.4$; all $p>0.2$ ), nor across the whole striatum $(\mathrm{tau}=0.09$; $p=0.72)$.

\section{Lack of relationship between positive affective and} drug-liking/wanting and other variables

The effects described could not be accounted for by positive affective or drug-liking/wanting effects of methylphenidate. No significant correlations were found between any of the measures significantly affected by drug and either cognitive performance measure or either ventral striatal or postcommissural caudate BP (all $p>0.05$ ).

\section{Discussion}

We combined psychopharmacology with neurochemical PET imaging, demonstrating for the first time that dissociable effects of methylphenidate on different aspects of cognition are accompanied by changes in $D_{2} / D_{3}$ receptor availability in distinct stri- 
atal subregions. Significant changes in caudate nucleus accompanied druginduced changes in reversal learning, whereas significant changes in ventral striatum accompanied drug-induced changes in spatial working memory. Receptor availability reflects an interaction between receptor concentration and extracellular dopamine concentration; dopamine release after drug administration results in radioligand displacement, measurable as reduced binding potential. The findings support the hypothesis that methylphenidate affects different cognitive tasks by modulating distinct fronto-striatal loops with distinct optimal dopamine levels and provide a neurobiological account of within-subject variability in drug effects across different cognitive tasks.

Our data extend previous observations that dopaminergic drug effects can also be predicted from individual differences in trait impulsivity as measured with BIS-11 (Cools et al., 2007b). Specifically, previous research has revealed that the dopamine $\mathrm{D}_{2}$ receptor agonist bromocriptine improved a form of task switching and potentiated striatal activity in high-impulsive subjects but not in low-impulsive subjects. Here, we extend this finding to the catecholamine indirect agonist methylphenidate, with important implications for understanding its cognitive enhancing effects in ADHD. Notably, methylphenidate improved reversal learning in high-impulsive subjects to a significantly greater extent than in low-impulsive subjects.

Our data also clarify mechanisms underlying cognitive effects of dopaminergic medications in healthy individuals, with implications for disorders including Parkinson's disease and schizophrenia, as well as ADHD. They are consistent with the hypothesis that, as in prefrontal cortex (Williams and Goldman-Rakic, 1995; Arnsten and Goldman-Rakic, 1998), different striatal sectors are optimally "tuned" to different levels of dopamine activity according to the Yerkes-Dodson principle, to mediate distinct cognitive functions.

Individual effects of methylphenidate on reversal learning were variable. However, this variability was resolved when the degree of raclopride displacement in the postcommissural caudate nucleus was taken into account. The greatest degree of raclopride displacement was associated with poorer performance under methylphenidate and the least displacement with superior performance compared with placebo. This anatomical locus of the effect of methylphenidate on reversal learning via dopamine $\mathrm{D}_{2} / \mathrm{D}_{3}$ receptors is consistent with other lines of evidence. For example, this region of the striatum has been found to be associated with reversal learning in monkeys bearing lesions of the caudate nucleus (Divac et al., 1967). Consistent with an effect at striatal dopamine receptors, raclopride administration in rhesus monkeys produced marked reversal learning impairments (Lee et al., 2007), and in humans, L-DOPA impaired probabilistic reversal learning in patients with Parkinson's disease (Swainson et al., 2000; Cools et al., 2001) and abolished the reversal-related blood oxygen level-dependent (BOLD) signal in the nucleus accumbens (Cools et al., 2007a).

Some previous studies have found an association between this task and more ventral striatal regions. For example, a functional imaging study using PET with $\mathrm{H}_{2}{ }^{15} \mathrm{O}$ showed that reversal learning was associated with increased regional blood flow within the ventral caudate nucleus (Rogers et al., 2000); also, a pharmaco-
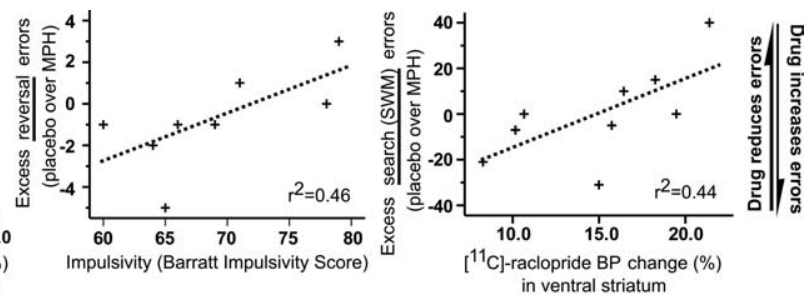

in ventral striatum

Figure 4. Left, Scatter plot showing an association between drug-induced reduction in $D_{2} / D_{3}$ receptor availability in postcomerrors, ordinate). Middle, Scatter plot showing an association between impulsivity (Barratt Impulciation between drug-induced reduction in $\mathrm{D}_{2} / \mathrm{D}_{3}$ receptor availability in the ventral striatum (abscissa) and improvement in SWM rdinate)

logical fMRI study of reversal learning (Dodds et al., 2008) showed that methylphenidate modulated the striatal BOLD response associated with reversal learning, with the precise location of this modulation in the ventral putamen. This variability of localization of reversal-associated functional imaging responses parallels variable localization of reward-related responses detected with fMRI (McClure et al., 2003; O’Doherty et al., 2003; Knutson et al., 2005), possibly reflecting the relative imprecision of activation localization with fMRI attributable to suboptimal normalization procedures (Brett et al., 2002). Furthermore, drug effects on dopamine receptors may not necessarily occur in those regions most active in a task (and therefore associated with functional MRI BOLD signal change) either under control or medicated conditions.

In contrast to the direction of the BP relationship with reversal learning, SWM performance was superior to placebo at the greatest level of raclopride displacement in ventral striatum. SWM is often linked with dorsolateral (dl-) PFC function in humans and might thus be expected to be related to the striatal projection zone of the dl-PFC, the caudate nucleus. Indeed, Levy et al. (1997) found that local cerebral glucose utilization rates were increased in the head of the caudate nucleus of monkeys performing the spatial delayed response task. This concurs with evidence for increased raclopride displacement in dorsal caudate during SWM in seven normal controls in a recent PET study (Sawamoto et al., 2008). However, in the latter study, there was also marginally significant raclopride displacement associated with SWM in ventral striatum, showing that such tasks may recruit more than one striatal subregion. This is compatible with the locus of raclopride displacement in the ventral striatum (nucleus accumbens) in the present study. The nucleus accumbens has also been associated with SWM function in several animal studies, for example in delayed alternation-type paradigms in a $\mathrm{T}$ maze (Taghzouti et al., 1985) or radial maze setting (Floresco et al., 1997). The precise aspect of working memory associated with ventral striatal raclopride displacement is not clear: a motivational effect may be possible, although none of the subjective mood or "liking" scales were associated with ventral striatal raclopride displacement. This lack of effect may have derived from using the oral rather than the intravenous route, which we chose to simulate the likely clinical effects of methylphenidate in ADHD.

The differential effects of methylphenidate on SWM and reversal learning suggest that these tasks engage different striatal regions that are optimally modulated by different levels of dopamine activity. This pattern of findings is consistent with previous hypotheses (Swainson et al., 2000; Cools et al., 2001) concerning 
differential effects of L-DOPA on cognitive functioning in Parkinson's disease. In those studies, L-DOPA improved some aspects of cognitive function (e.g., SWM and task-set switching) but impaired reversal learning. Those results were explained in terms of the gradient of dopamine loss from dorsal to ventral striatum in Parkinson's disease, the nucleus accumbens being relatively spared (Kish et al., 1988). L-DOPA was hypothesized to produce an "over-dosing" of this region, in relation to other areas that were depleted, implicating multiple inverted U-shaped curves associated with distinct cognitive functions. These findings, together with the present data, can be interpreted in terms of the original form of the Yerkes-Dodson relationship (Yerkes and Dodson, 1908), which postulates that different tasks will have different optima for performance. The data are also consistent with evidence from monkeys (Roberts et al., 1994; Collins et al., 1998) and rodents (Floresco et al., 1997; Chudasama and Robbins, 2004; Chudasama et al., 2005) that different cognitive tasks may be differentially modulated by central dopamine (although most of those examples involved manipulations of dopamine in the PFC). Together with the observation that bromocriptine has opposite effects on spatial SWM and reversal learning in healthy volunteers (Mehta et al., 2001), the contrasting effects of methylphenidate in the present study suggest that the different sensitivity of these tasks is not simply related to differences in striatal dopamine depletion, as occurs in Parkinson's disease. Instead, they may reflect modulation of distinct striatal subregions with different optimal dopamine levels.

There were some limitations of the present study. First, we were only able to test a relatively small sample of subjects both on placebo and methylphenidate. This sample size is not unusual for PET studies and was demonstrated to be sufficiently large to reveal statistically robust correlations. Second, we were limited to testing only one dose of methylphenidate in addition to placebo. It is important to note that we replicate previous PET studies using psychostimulants, which reported that D-amphetamine in humans (Drevets et al., 2001; Martinez et al., 2003) and in the baboon (Drevets et al., 1999), as well as intravenous methylphenidate in humans (Udo de Haes et al., 2005), produced the greatest overall changes in BP in ventral striatum and putamen. Future dose-response designs will be necessary to confirm the inverted $\mathrm{U}$-shaped functions that we have postulated.

The inverted U-shaped function is also compatible with evidence from studies by Volkow et al. (1999) on euphorigenic effects of intravenous methylphenidate in normal volunteers. Those authors found that subjects with relatively lower striatal $\mathrm{D}_{2} / \mathrm{D}_{3}$ receptor density as measured using raclopride experienced positive effects of the drug, whereas those with relatively high striatal binding found it aversive. This is consistent with findings in rats that low binding of the $\mathrm{D}_{2} / \mathrm{D}_{3}$ radioligand $[18 \mathrm{~F}]$-fallypride in the nucleus accumbens was correlated with an increased propensity to self-administer cocaine (Dalley et al., 2007). The rats with low accumbens binding were also impulsive, even before cocaine exposure, which may relate to the findings that effects of bromocriptine (Cools et al., 2007b) as well as those of methylphenidate (present study) were dependent on baseline impulsivity measures, as measured using BIS-11. Apart from theoretical implications of the present findings, there are some clinical implications. Notably, methylphenidate can clearly exert detrimental as well as beneficial effects on cognition at the same dose in the same individual, depending on the nature of the cognitive task. Furthermore, beneficial effects appear to be stronger in subjects with higher baseline impulsivity, possibly related to the generally therapeutic effects of this compound in ADHD.

\section{References}

Arnsten AF, Goldman-Rakic PS (1998) Noise stress impairs prefrontal cortical cognitive function in monkeys: evidence for a hyperdopaminergic mechanism. Arch Gen Psychiatry 55:362-368.

Aron AR, Dowson JH, Sahakian BJ, Robbins TW (2003) Methylphenidate improves response inhibition in adults with attention-deficit/hyperactivity disorder. Biol Psychiatry 54:1465-1468.

Bedard AC, Ickowicz A, Logan GD, Hogg-Johnson S, Schachar R, Tannock R (2003) Selective inhibition in children with attention-deficit hyperactivity disorder off and on stimulant medication. J Abnorm Child Psychol 31:315-327.

Brett M, Johnsrude IS, Owen AM (2002) The problem of functional localization in the human brain. Nat Rev 3:243-249.

Chudasama Y, Robbins TW (2004) Psychopharmacological approaches to modulating attention in the five-choice serial reaction time task: implications for schizophrenia. Psychopharmacology (Berl) 174:86-98.

Chudasama Y, Nathwani F, Robbins TW (2005) D-amphetamine remediates attentional performance in rats with dorsal prefrontal lesions. Behav Brain Res 158:97-107.

Collins P, Roberts AC, Dias R, Everitt BJ, Robbins TW (1998) Perseveration and strategy in a novel spatial self-ordered sequencing task for nonhuman primates: effects of excitotoxic lesions and dopamine depletions of the prefrontal cortex. J Cogn Neurosci 10:332-354.

Cools R, Barker RA, Sahakian BJ, Robbins TW (2001) Enhanced or impaired cognitive function in Parkinson's disease as a function of dopaminergic medication and task demands. Cereb Cortex 11:1136-1143.

Cools R, Clark L, Robbins TW (2004) Differential responses in human striatum and prefrontal cortex in object and rule relevance. J Neurosci 24:1129-1135.

Cools R, Lewis SJ, Clark L, Barker RA, Robbins TW (2007a) L-DOPA disrupts activity in the nucleus accumbens during reversal learning in Parkinson's disease. Neuropsychopharmacology 32:180-189.

Cools R, Sheridan M, Jacobs E, D'Esposito M (2007b) Impulsive personality predicts dopamine-dependent changes in frontostriatal activity during component processes of working memory. J Neurosci 27:5506-5514.

Dalley JW, Fryer TD, Brichard L, Robinson ES, Theobald DE, Lääne K, Peña Y, Murphy ER, Shah Y, Probst K, Abakumova I, Aigbirhio FI, Richards HK, Hong Y, Baron JC, Everitt BJ, Robbins TW (2007) Nucleus accumbens $\mathrm{D} 2 / 3$ receptors predict trait impulsivity and cocaine reinforcement. Science 315:1267-1270.

Dias R, Robbins TW, Roberts AC (1996) Dissociation in prefrontal cortex of affective and attentional shifts. Nature 380:69-72.

Divac I, Rosvold HE, Szwarcbart MK (1967) Behavioral effects of selective ablation of the caudate nucleus. J Comp Physiol Psychol 63:184-190.

Dodds CM, Müller U, Clark L, van Loon A, Cools R, Robbins TW (2008) Methylphenidate has differential effects on blood oxygenation leveldependent signal related to cognitive subprocesses of reversal learning. J Neurosci 28:5976-5982.

Drevets WC, Price JC, Kupfer DJ, Kinahan PE, Lopresti B, Holt D, Mathis C (1999) PET measures of amphetamine-induced dopamine release in ventral versus dorsal striatum. Neuropsychopharmacology 21:694-709.

Drevets WC, Gautier C, Price JC, Kupfer DJ, Kinahan PE, Grace AA, Price JL, Mathis CA (2001) Amphetamine-induced dopamine release in human ventral striatum correlates with euphoria. Biol Psychiatry 49:81-96.

Floresco SB, Seamans JK, Phillips AG (1997) Selective roles for hippocampal, prefrontal cortical, and ventral striatal circuits in radial-arm maze tasks with or without a delay. J Neurosci 17:1880-1890.

Gunn RN, Lammertsma AA, Hume SP, Cunningham VJ (1997) Parametric imaging of ligand-receptor binding in PET using a simplified reference region model. Neuroimage 6:279-287.

Haber SN, Kim KS, Mailly P, Calzavara R (2006) Reward-related cortical inputs define a large striatal region in primates that interface with associative cortical connections, providing a substrate for incentive-based learning. J Neurosci 26:8368-8376.

Hume SP, Gunn RN, Jones T (1998) Pharmacological constraints associated with positron emission tomographic scanning of small laboratory animals. Eur J Nucl Med 25:173-176.

Kempton S, Vance A, Maruff P, Luk E, Costin J, Pantelis C (1999) Executive function and attention deficit hyperactivity disorder: stimulant medication and better executive function performance in children. Psychol Med 29:527-538.

Kimberg DY, D’Esposito M, Farah MJ (1997) Effects of bromocriptine on 
human subjects depend on working memory capacity. Neuroreport 8:3581-3585.

Kinahan PE, Rogers JG (1989) Analytic 3D image reconstruction using all detected events. IEEE Trans Nucl Sci 36:964-968.

Kish SJ, Shannak K, Hornykiewicz O (1988) Uneven pattern of dopamine loss in the striatum of patients with idiopathic Parkinson's disease. Pathophysiologic and clinical implications. N Engl J Med 318:876-880.

Knutson B, Taylor J, Kaufman M, Peterson R, Glover G (2005) Distributed neural representation of expected value. J Neurosci 25:4806-4812.

Kruskal WH (1958) Ordinal measures of association. J Am Stat Assoc 53:814-861.

Lee B, Groman S, London ED, Jentsch JD (2007) Dopamine D2/D3 receptors play a specific role in the reversal of a learned visual discrimination in monkeys. Neuropsychopharmacology 32:2125-2134.

Levy R, Friedman HR, Davachi L, Goldman-Rakic PS (1997) Differential activation of the caudate nucleus in primates performing spatial and nonspatial working memory tasks. J Neurosci 17:3870-3882.

Lewis SJ, Dove A, Robbins TW, Barker RA, Owen AM (2004) Striatal contributions to working memory: a functional magnetic resonance imaging study in humans. Eur J Neurosci 19:755-760.

Martinez D, Slifstein M, Broft A, Mawlawi O, Hwang DR, Huang Y, Cooper T, Kegeles L, Zarahn E, Abi-Dargham A, Haber SN, Laruelle M (2003) Imaging human mesolimbic dopamine transmission with positron emission tomography. Part II: amphetamine-induced dopamine release in the functional subdivisions of the striatum. J Cereb Blood Flow Metab 23:285-300.

Mattay VS, Goldberg TE, Fera F, Hariri AR, Tessitore A, Egan MF, Kolachana B, Callicott JH, Weinberger DR (2003) Catechol O-methyltransferase val158-met genotype and individual variation in the brain response to amphetamine. Proc Natl Acad Sci U S A 100:6186-6191.

Mawlawi O, Martinez D, Slifstein M, Broft A, Chatterjee R, Hwang DR, Huang Y, Simpson N, Ngo K, Van Heertum R, Laruelle M (2001) Imaging human mesolimbic dopamine transmission with positron emission tomography: I. Accuracy and precision of $\mathrm{D}(2)$ receptor parameter measurements in ventral striatum. J Cereb Blood Flow Metab 21:1034-1057.

McClure SM, Berns GS, Montague PR (2003) Temporal prediction errors in a passive learning task activate human striatum. Neuron 38:339-346.

Mehta MA, Owen AM, Sahakian BJ, Mavaddat N, Pickard JD, Robbins TW (2000) Methylphenidate enhances working memory by modulating discrete frontal and parietal lobe regions in the human brain. J Neurosci 20:RC65.

Mehta MA, Swainson R, Ogilvie AD, Sahakian BJ, Robbins TW (2001) Improved short-term spatial memory but impaired reversal learning following the dopamine $\mathrm{D}(2)$ agonist bromocriptine in human volunteers. Psychopharmacology (Berl) 159:10-20.

O’Doherty JP, Dayan P, Friston K, Critchley H, Dolan RJ (2003) Temporal difference models and reward-related learning in the human brain. Neuron 38:329-337.

Owen AM, Downes JJ, Sahakian BJ, Polkey CE, Robbins TW (1990) Planning and spatial working memory following frontal lobe lesions in man. Neuropsychologia 28:1021-1034.

Patton JH, Stanford MS, Barratt ES (1995) Factor structure of the Barratt impulsiveness scale. J Clin Psychol 51:768-774.
Robbins TW, Owen AM, Sahakian BJ (1998) The neuropsychology of basal ganglia disorders: an integrated cognitive and comparative approach. In: Disorders of mind and brain (Ron M, David A, eds), pp 57-83. Cambridge, UK: Cambridge UP.

Roberts AC, De Salvia MA, Wilkinson LS, Collins P, Muir JL, Everitt BJ, Robbins TW (1994) 6-Hydroxydopamine lesions of the prefrontal cortex in monkeys enhance performance on an analog of the Wisconsin Card Sort Test: possible interactions with subcortical dopamine. J Neurosci 14:2531-2544.

Rogers RD, Andrews TC, Grasby PM, Brooks DJ, Robbins TW (2000) Contrasting cortical and subcortical activations produced by attentional-set shifting and reversal learning in humans. J Cogn Neurosci 12:142-162.

Rousset OG, Ma Y, Evans AC (1998) Correction for partial volume effects in PET: principle and validation. J Nucl Med 39:904-911.

Sawamoto N, Piccini P, Hotton G, Pavese N, Thielemans K, Brooks DJ (2008) Cognitive deficits and striato-frontal dopamine release in Parkinson's disease. Brain 131:1294-1302.

Swainson R, Rogers RD, Sahakian BJ, Summers BA, Polkey CE, Robbins TW (2000) Probabilistic learning and reversal deficits in patients with Parkinson's disease or frontal or temporal lobe lesions: possible adverse effects of dopaminergic medication. Neuropsychologia 38:596-612.

Taghzouti K, Louilot A, Herman JP, Le Moal M, Simon H (1985) Alternation behavior, spatial discrimination, and reversal disturbances following 6-hydroxydopamine lesions in the nucleus accumbens of the rat. Behav Neural Biol 44:354-363.

Udo de Haes JI, Kortekaas R, Van Waarde A, Maguire RP, Pruim J, den Boer JA (2005) Assessment of methylphenidate-induced changes in binding of continuously infused $[(11) \mathrm{C}]$-raclopride in healthy human subjects: correlation with subjective effects. Psychopharmacology (Berl) 183:322-330.

Vaidya CJ, Austin G, Kirkorian G, Ridlehuber HW, Desmond JE, Glover GH, Gabrieli JD (1998) Selective effects of of methylphenidate in attention deficit hyperactivity disorder: a functional magnetic resonance study. Proc Natl Acad Sci U S A 95:14494-14499.

Vijayraghavan S, Wang M, Birnbaum SG, Williams GV, Arnsten AF (2007) Inverted-U dopamine D1 receptor actions on prefrontal neurons engaged in working memory. Nat Neurosci 10:376-384.

Volkow ND, Wang GJ, Fowler JS, Logan J, Gatley SJ, Gifford A, Hitzemann R, Ding YS, Pappas N (1999) Prediction of reinforcing responses to psychostimulants in humans by brain dopamine D2 receptor levels. Am J Psychiatry 156:1440-1443.

Volkow ND, Wang G, Fowler JS, Logan J, Gerasimov M, Maynard L, Ding Y, Gatley SJ, Gifford A, Franceschi D (2001) Therapeutic doses of oral methylphenidate significantly increase extracellular dopamine in the human brain. J Neurosci 21:RC121.

von Huben SN, Davis SA, Lay CC, Katner SN, Crean RD, Taffe MA (2006) Differential contributions of dopaminergic D1- and D2-like receptors to cognitive function in rhesus monkeys. Psychopharmacology (Berl) 188:586-596.

Williams GV, Goldman-Rakic PS (1995) Modulation of memory fields by dopamine D1 receptors in prefrontal cortex. Nature 376:572-575.

Yerkes RM, Dodson JD (1908) The relation of strength of stimulus to rapidity of habit formation. J Comp Neurol Psychol 18:459-482. 